Results ACL injured and uninjured skiers did not differ regarding ski length to height ratio $(95.3 \pm 4.6$ vs. $94.9 \pm 3.8 \%$, $\mathrm{p}=.503)$ or side cut radius $(13.9 \pm 2.0$ vs. $14.4 \pm 2.7 \mathrm{~m}$, $\mathrm{p}=.243)$. Compared to uninjured skiers, ACL injured skiers had a significantly lower absolute mean $\mathrm{H}_{\mathrm{F}}(40.7 \pm 5.7$ vs. $38.3 \pm 4.8 \mathrm{~mm}, \mathrm{p}<.001, d=0.44)$ and $\mathrm{H}_{\mathrm{B}}(44.9 \pm 6.7$ vs. 39.2 $\pm 5.1 \mathrm{~mm}<<.001, d=0.82)$ and a higher quotient $\mathrm{H}_{\mathrm{F}} / \mathrm{H}_{\mathrm{B}}$ $(0.91 \pm 0.08$ vs. 0.98 vs, $\mathrm{p}<.001, d=0.75)$. Moreover, a lower absolute mean $\mathrm{H}_{\mathrm{T}}(16.8 \pm 2.3$ vs. $13.8 \pm 1.6 \mathrm{~mm}, \mathrm{p}<.001$, $d=1.19)$ and $\mathrm{H}_{\mathrm{H}}(26.8 \pm 2.6$ vs. $24.2 \pm 1.9 \mathrm{~mm}, \mathrm{p}<.001$, $d=0.99)$ and a lower quotient $\mathrm{H}_{\mathrm{T}} / \mathrm{H}_{\mathrm{H}}(0.63 \pm 0.09$ vs. 0.57 $\pm 0.06, \mathrm{p}<.001, d=0.65)$ of the ski boots were found in ACL injured skiers.

Conclusions ACL injured and uninjured skiers differed significantly regarding ski boot sole abrasion and combined height of ski and binding plate, which should be considered as potential risk factors for ACL injuries among recreational skiers.

\section{USING TIME TO EVENT METHODS TO EVALUATE SPORTS PARTICIPATION, SPECIALIZATION, AND INJURY}

Julie Agel, Todd Rockwood, Anne Eaton. University of Minnesota, Minneapolis, USA

\subsection{6/bjsports-2021-IOC.318}

Background Sport specialization is being widely implicated as a cause of increasing youth injury and drop out rates. No published data encompasses the variety of variables that define the individual athletes' sports participation history. The literature currently evaluates the impact of sports specialization on injury using univariate analysis. There are multiple potential factors that impact injury that need to be considered.

Objective To develop an appropriate analysis plan to determine the impact of sports specialization compared to multiple sport participation on injury incorporating age at which sport participation began in the sport specialized in and age at which specialization in the target sport relative to current age as a function of duration of participation in years.

Design Statistical Analysis Comparisons.

Setting Academic University.

Patients (or Participants) Professional athletes.

Interventions (or Assessment of Risk Factors) Yrs of participation, specialization, current age.

Main Outcome Measurements Impact of Sport Specialization.

Results We compare the assumptions and results of modelling the time to event outcome sports injury with different analysis methods and time scales. The relationship between the time scale and the outcome is non-parametric and very flexible, while the relationships between adjustment variables and the outcome are not as flexible if standard modelling approaches are used (Cox model). Investigators should weigh this and their scientific question of interest when selecting an analysis approach. In our scenario, we felt that modelling time to injury with a time varying covariate representing specialization, possibly adjusted for the age participants started the main sport, with time to injury measured from the age that the individual started playing their main sport, provided useful insight into the impact of sports specialization compared to multiple sport participation on injury.

Conclusions The presented methodology is a recommendation for future researchers to consider when collecting and presenting data.

\section{RECORDING INJURIES ONLY DURING WINTER COMPETITIVE SEASON UNDERESTIMATES INJURY INCIDENCE IN ELITE ATHLETES OF THE FRENCH SKI FEDERATION: A TWO-YEAR PROSPECTIVE COHORT STUDY}

${ }^{1,2}{ }^{2}$ Nicolas Bouscaren, ${ }^{1,3}$ Alice Guyon, ${ }^{1,3}$ Stephane De Jesus. ${ }^{1}$ French Ski Federation, Annecy, France; ${ }^{2}$ Centre d'Investigation Clinique Inserm CIC 1410 Epidémiologie Clinique, Saint Pierre, Reunion (France); ${ }^{3}$ Centre de Médecine du Sport de Haut Niveau, Albertville, France

\subsection{6/bjsports-2021-IOC.319}

Background The implementation of an optimal injury prevention program is based primarily on a solid epidemiological injury surveillance system. Current epidemiological studies in skiing disciplines of International Skiing Federation are limited to retrospective surveys only on winter competitive season (WCS).

Objective The aim of this study was to determine the pattern of injuries in elite athletes of French Ski Federation (FFS) during the winter competitive season and the summer off-season (SOS).

Design Two-year prospective cohort study.

Setting and participants Data of two complete seasons, from 1 May 2017 to 31 April 2018, within elite athletes of FFS (alpine skiing, freestyle skiing, snowboarding, ski jumping, biathlon and crosscountry skiing) were recorded. WCS and SOS were defined from 1 November to 31 April, and from 1 May to 31 October respectively.

Main Outcome Measurements Injury was defined as any physical complaint during training or competition. Each injury was further categorised by location, mechanism, structure, severity and circumstances. Diagnoses were provided by the team doctor according to Orchard Sports Injury Classification.

Results During the study period (2017-2019), 647 skiers-season, $421(65.1 \%)$ males and 226 (34.9\%) females, were covered. In total, 352 injuries were recorded. Of theses 235 (66.8\%) injuries occurred during WCS and 117 (26.4\%) during SOS. The higher absolute injury incidences were 110.1 (88.2-135.8) injuries per 100 athletes per seasons in snowboarding, $84.7(66.3-106.7)$ in freestyle skiing and 51.6 (43.1-61.1) in alpine skiing. In our sample, 145 (41.2\%) of injuries were severe ( $>28$ days of absence). The most frequent injury localisations were knee (20.7\%), ankle (16.8\%) and head/face (11.9\%). Joint/ligament injuries represented $46 \%$ of all injuries. Over the study period, 34 concussions and 1 death were recorded.

Conclusions Recording elite athlete injuries only during the competition period is not sufficient. To not record summer off-season injuries among elite FFS athletes would result in more than $25 \%$ of injuries being missed and would hinder the implementation of an optimal preventive policy.

\section{TWO-YEAR HEALTH SURVEILLANCE AND RECOMMENDED METHODS FOR AN INTERNATIONAL SHORT-TRACK SPEED SKATING TEAM}

Michael Brownlow, Steve McCaig. English Institute of Sport, Nottingham, UK

\subsection{6/bjsports-2021-IOC.320}

Background Health risk mitigation strategies in sport commence with establishing injury and illness burden trends. There is little health surveillance data to inform threats to Short Track Speed Skating (STSS) training and performance. 